\title{
Hubungan Pengetahuan Ibu Post Sectio Caesarea dan Dukungan Suami dengan Pelaksanaan Mobilisasi Dini
}

\author{
Elfira Sri Futriani ${ }^{1}$, Sri Baeti Janati ${ }^{2}$ \\ ${ }^{1,2}$ Program Studi S1 Keperawatan Sekolah Tinggi Ilmu Kesehatan Abdi Nusantara Jakarta \\ Jl. Raya Kalimalang NO 12 A-C Pondok Kelapa, Jakarta \\ Email : ${ }^{1}$ elfirasrifutriani21@gmail.com, ${ }^{2}$ sribaetijanati@gmail.com
}

\begin{abstract}
Abstrak
Mobilisasi dini adalah sesegra mungkin membimbing ibu keluar dari tempat tidurnya dan membimbing ibu sesegra mungkin bisa berjalan secara bertahap. Agar proses mobilisasi ini dapat berjalan dengan baik sangat terkait dengan pengetahuan ibu post partum dengan secsio cesaria dan dukungan suami.Tujuan penelitian adalah untuk mengetahui hubungan pengetahuan ibu post sectio caesarea dan dukungan suami dengan pelaksanaan mobilisasi dini di RS Anna Medika Bekasi tahun 2018. Metode penelitian yang digunakan adalah analitik dengan pendekatan cross sectional. Sampel dalam penelitian ini adalah seluruh ibu post sectio caesarea di RS Anna Medika Bekasi yang dirawat pada tanggal 26 Januari s/d 20 Februari 2018 sebanyak 50 orang. Berdasarkan hasil penelitian analisis univariat terbanyak pada responden yang melakukan mobilisasi dini $(80 \%)$, pengetahuan baik $(56 \%)$ dan mendapat dukungan dari suami (62\%). Analisis bivariat menunjukkan adanya hubungan pengetahuan $(\mathrm{Pv}=0,00 \mathrm{I})$ dan dukungan suami $(\mathrm{Pv}=0,007)$ dengan pelaksanaan mobilisasi dini. Diharapkan kepada suami agar memberikan dukungan kepada pasien pasca operasi SC.
\end{abstract}

Kata kunci : Buang Air Besar Sembarangan, Pengetahuan, Sarana, Sosial Ekonomi

\begin{abstract}
Early mobilization as soon as possible leads the mother out of bed and guiding the mother as soon as possible to walk completely. In order for this mobilization process to work properly, it is closely related to the knowledge of post partum mothers with cesaria and husband's support. The aim of this research is to know relations knowledge mother post sectio of cæsarea and support husband to the implementation of the mobilization of early in the hospital anna medika bekasi 2018. Research methods that were used is analytic. In this research was sample for the post of caesarea sectio at the hospital anna medika bekasi who are treated on january 26, up to 20 february 2018 some 50 people. Based on the research done in univariat most analysis of respondents who make mobilization of early (80\%), of knowledge of good ( $56 \%$ ) and received support from their husband $62 \%$ ). Bivariat analysis shows the connection knowledge $(p$ Value $=0,001)$ and support husband ( $p$ value $=0,007$ ) to the implementation of the mobilization of early. It is expected that the husband will provide support to patients after SC surgery.
\end{abstract}

Keywords : Knowledge, husband support, mobilization of the early 


\section{Pendahuluan}

Organisasi kesehatan tingkat dunia World Health Organization (WHO) memperkirakan 800 perempuan meninggal setiap harinya akibat komplikasi kehamilan dan proses kelahiran. Sekitar 99\% dari seluruh kematian ibu terjadi di negara berkembang. Sekitar $80 \%$ kematian maternal merupakan akibat meningkatnya komplikasi selama kehamilan, persalinan dan setelah persalinan. Menurut laporan WHO yang telah dipublikasikan pada tahun 2014 Angka Kematian Ibu (AKI) di dunia mencapai angka 289.000 jiwa. Di mana terbagi atas beberapa Negara, antara lain Amerika Serikat mencapai 9300 jiwa, Afrika Utara 179.000 jiwa dan Asia Tenggara 16.000 jiwa. $^{1}$

Untuk AKI di negara-negara Asia Tenggara diantaranya Filipina 112 per 100.000 kelahiran hidup, Vietnam 160 per 100.000 kelahiran hidup, Thailand 44 per 100.000 kelahiran hidup, Brunei 60 per 100.000 kelahiran hidup, dan Malaysia 160 per 100.000 kelahiran hidup, sedangkan di Indonesia 305 per 100.000 kelahiran hidup. $^{2}$

Wilayah yang paling banyak terdapat angka kematian ibu di Indonesia pada tahun 2014 adalah Jawa Barat sebanyak 837 orang. Peringkat kedua ditempati Jawa Tengah sebesar 668 orang, lalu Jawa Timur 627 orang, Banten 250 orang, serta Nusa Tenggara Timur (NTT) 208 orang. Sementara Papua berada diurutan ke 4 dengan jumlah 422/100.000 KH. ${ }^{3}$

Menurut Depkes RI pada tahun 2015, penyebab langsung kematian maternal di Indonesia terkait kehamilan dan persalinan terutama yaitu perdarahan $28 \%$. Sebab lain, yaitu eklampsi $24 \%$, infeksi $11 \%$, partus lama $5 \%$, dan abortus $5 \%$. Sedangkan penyebab utama terjadinya kematian ibu di Provinsi DKI Jakarta tahun 2014 yaitu Hipertensi Dalam kehamilan/Eklampsia (39\%), Pendarahan $(31 \%)$ disebabkan oleh faktor anemia ibu hamil, Infeksi (6\%), Abortus (2\%), Partus lama $(1 \%)$ dan penyebab lainnya. ${ }^{4}$
Persalinan yang dilakukan dengan operasi membutuhkan rawat inap yang lebih lama dirumah sakit. Hal ini tergantung dari cepat lambatnya kesembuhan ibu akibat proses pembedahan selama masa pemulihan berlangsung, ibu akan mengalami berbagai masalah dan dapat berlanjut pada komplikasi masa nifas merupakan penyebab kematian nomer dua setelah perdarahan. ${ }^{5}$

Mobilisasi dini adalah suatu upaya membimbing kemandirian pasien sedini mungkin untuk mempertahankan fungsi fisiologis. Mobilisasi dini dilakukan secara bertahap yaitu dimulai dengan gerakan miring kanan dan kiri,kemudian ibu dapat duduk pada hari kedua, menggerakkan kaki dan berjalan dapat dilakukan pada hari ketiga. Pasien dengan sectio caesarea (SC) bisa memulai ambulasi setelah 24-36 jam sesudah melahirkan. ${ }^{6}$

Mobilisasi bermanfaat untuk menormalkan sirkulasi didalam tubuh. Selain itu mobilisasi dini bermanfaat untuk meningkatkan fungsi pencernaan, fungsi kandung kemih menjadi lebih baik, mempercepat penyembuhan luka, penderita merasa lebih sehat dan lebih kuat. $^{7}$

Dampak tidak melakukan mobilisasi dini akan terjadi peningkatan suhu tubuh karena adanya involutio uterus yang tidak baik sehingga sisa darah tidak dapat dikeluarkan dan menyebabkan infeksi. Jika terjadi komplikasi pasca bedah seperti infeksi maka akan membutuhkan waktu lama untuk proses penyembuhan luka dan bahkan bisa sampai terjadi sepsis sehingga berdampak pada kematian maternal masa nifas. $^{8}$

Faktor-faktor yang mempengaruhi pelaksanaan mobilisasi dini pada post sectio caesarea antara lain faktor internal yaitu ibu takut jahitan akan lepas jika bergerak kelelahan saat mengalami partus lama, pengetahuan, usia, nyeri, motivasi ibu untuk melakukan mobilisasi dini, gaya hidup, emosi. Faktor eksternal antara lain dukungan suami dan keluarga, kebudayaan yang melarang bergerak dan kaki harus 
lurus, sosial ekonomi, pelayanan yang diberikan petugas. ${ }^{9}$

Tingkat pengetahuan merupakan faktor yang berperan penting dalam mewujudkan pelaksanaan mobilisasi dini setelah melahirkan. Jika tingkat pengetahuan seseorang rendah terhadap manfaat dan tujuan dari mobilisasi dini, maka hal itu akan sangat mempengaruhi pada tingkat pelaksanaannya. Selain pengetahuan dukungan suami juga merupakan suatu bentuk perwujudan dari sikap perhatian dan kasih sayang. Dukungan suami memiliki andil yang cukup besar dalam menentukan status kesehatan ibu. Dukungan suami yang baik dapat memberikan motivasi yang baik pada ibu untuk melakukan mobilisasi dini. Keberadaan dukungan suami yang kuat terbukti, lebih mudah sembuh dari sakit, fungsi kognitif, fisik, dan kesehatan emosi, memberikan support, penghargaan, perhatian, dan terutama untuk mobilisasi dini. ${ }^{10}$

Dukungan suami juga sangat penting untuk motivasi pasien dalam menjalankan mobilisasi, pada kenyataannya banyak keluarga yang kurang mengerti bagaimana cara merawat keluarga yang sakit. Oleh karena itu peran suami sangat perlu sekali dalam rangka untuk memberikan dukungan terhadap pasien supaya terbebas dari penyakit dan komplikasi yang mungkin timbul setelah pasca operasi sectio caesarea. ${ }^{11}$

Berdasarkan data dari Rumah Sakit Anna Medika, jumlah ibu bersalin dengan sectio caesarea pada tahun 2016 sebanyak 416 orang, dan pada tahun 2017 mengalami peningkatan menjadi 735 orang. Hasil survey awal yang dilakukan peneliti pada tanggal 12 sampai dengan 25 November 2017 didapatkan data 42 pasien dengan persalinan sectio caesarea, dari 42 pasien itu diketahui hanya 26 pasien $(61,9 \%)$ yang melakukan mobilisasi dini sedangkan 16 pasien $(38,1 \%)$ tidak melaksanakan mobilisasi dini dengan alasan takut sakit.
Berdasarkan informasi dari bidan dan perawat di Ruang Melati RS Anna Medika bahwa ibu post sectio caesarea sebagian besar tidak melakukan mobilisasi dini karena kurangnya pengetahuan tentang mobilisasi dini dan tidak adanya dukungan dari suami. Atas dasar data tersebut maka penulis tertarik untuk melakukan penelitian tentang "Hubungan pengetahuan ibu post sectio caesarea dan dukungan suami dengan pelaksanaan mobilisasi dini di RS Anna Medika Bekasi tahun 2018".

\section{Metode}

Metode penelitian menggunakan analitik dengan pendekatan cross sectional. Pengambilan data dilakukan dengan data primer yaitu data yang diperoleh dari hasil penyebaran kuesioner. Instrumen pengambilan data yang digunakan adalah kuesioner. Populasi dalam penelitian ini adalah seluruh ibu post sectio caesarea di Ruang Melati RS Anna Medika Bekasi pada bulan Februari 2018 dengan jumlah sampel sebanyak 50 orang. Metode analisis yang digunakan adalah analisis univariat dan analisis bivariat dengan uji chi square.

\section{Hasil}

Penelitian ini dilaksanakan di RS Anna Medika Bekasi tahun 2018. Waktu penelitian dilaksanakan pada pada tanggal 26 Januari s/d 20 Februari 2018. Setelah dilakukan penelitian diperoleh data sebanyak 50 responden.

Tabel 1. Univariat

\begin{tabular}{llcc}
\hline Variabel & Kategori & n & \% \\
\hline Pengetahuan & Baik & 28 & 56 \\
& Cukup & 15 & 30 \\
& Kurang & 7 & 14 \\
Dukungan & Mendukung & 31 & 62 \\
suami & Tidak mendukung & 19 & 38 \\
Mobilisasi & Ya & 40 & 80 \\
Dini & Tidak & 10 & 20 \\
\hline
\end{tabular}


Tabel 2. Hubungan Pengetahuan Ibu dan dukungan suami Dengan Pelaksanaan Mobilsasi Dini di Ruang Melati RS Anna Medika Bekasi

\begin{tabular}{|c|c|c|c|c|c|c|c|c|}
\hline \multirow{3}{*}{ Variabel } & \multirow{3}{*}{ Kategori } & \multicolumn{4}{|c|}{ Mobilisasi Dini } & \multirow{2}{*}{\multicolumn{2}{|c|}{ Total }} & \multirow{3}{*}{ P. Value } \\
\hline & & \multicolumn{2}{|c|}{ Ya } & \multicolumn{2}{|c|}{ Tidak } & & & \\
\hline & & $\mathbf{n}$ & $\%$ & $\mathbf{n}$ & $\%$ & $\mathbf{N}$ & $\%$ & \\
\hline \multirow[t]{3}{*}{ Pengetahuan } & Baik & 25 & 89,3 & 3 & 10,7 & 28 & 100,0 & $\mathbf{0 , 0 0 1}$ \\
\hline & Cukup & 13 & 86,7 & 2 & 13,3 & 15 & 100,0 & \\
\hline & Kurang & 2 & 28,6 & 5 & 71,4 & 7 & 100,0 & \\
\hline \multirow[t]{2}{*}{ Dukungan Suami } & Mendukung & 29 & 93,5 & 2 & 6,5 & 31 & 100,0 & $\mathbf{0 , 0 0 7}$ \\
\hline & Tidak mendukung & 11 & 57,9 & 8 & 42,1 & 19 & 100,0 & \\
\hline
\end{tabular}

Dari tabel 1 diketahui bahwa pengetahuan ibu terkait pelaksanaan mobilisasi dini sebagian besar dalam kategori baik (56\%). Hanya $14 \%$ ibu dengan pengetahuan kurang dan sisanya berpengetahuan cukup. Sebagian besar suami mendukung istri untuk melakukan mobilisasi dini (62\%). Dari 50 orang ibu Post Sectio Caesarea terdapat $40 \mathrm{ibu}$ $(80 \%)$ yang melakukan mobilisasi dini.

Berdasarkan tabel 2 dapat diketahui bahwa dari 28 responden yang berpengetahuan baik terbanyak pada responden yang melakukan mobilisasi dini sebanyak 25 responden $(89,3 \%)$, dari 15 responden yang berpengetahuan cukup terbanyak pada responden yang melakukan mobilisasi dini sebanyak 13 responden $(86,7 \%)$, dan dari 7 responden yang berpengetahuan kurang terbanyak pada responden yang tidak melakukan mobilisasi dini sebanyak 5 responden $(71,4 \%)$. Hasil cross tabulasi antara variabel pengetahuan dengan mobilisasi dini menunjukan hasil uji statistik ChiSquare diperoleh nilai $p$ value 0,001 (p.value < 0,05) yang berarti Ho ditolak dan $\mathrm{Ha}$ diterima artinya ada hubungan yang bermakna antara pengetahuan dengan pelaksanaan mobilisasi dini.

Berdasarkan tabel 2 juga dapat diketahui bahwa dari 31 responden yang mendapatkan dukungan dari suami terbanyak pada responden yang melakukan mobilisasi dini sebanyak 29 responden $(93,5 \%)$, dan dari 19 responden yang tidak mendapatkan dukungan dari suami terbanyak pada responden yang melakukan mobilisasi dini sebanyak 11 responden $(57,9 \%)$. Hasil cross tabulasi antara variabel dukungan suami dengan mobilisasi dini menunjukan hasil uji statistik Chi-Square diperoleh nilai $p$ value 0,007 (p.value < 0,05) yang berarti $\mathrm{Ho}$ ditolak dan $\mathrm{Ha}$ diterima artinya ada hubungan yang bermakna antara dukungan suami dengan pelaksanaan mobilisasi dini.

\section{Pembahasan}

Hasil cross tabulasi antara variabel pengetahuan dengan mobilisasi dini menunjukan hasil uji statistik Chi-Square diperoleh nilai $p$ value $p$ value 0,001 (p.value < 0,05) yang berarti Ho ditolak dan $\mathrm{Ha}$ diterima artinya ada hubungan yang bermakna antara pengetahuan dengan pelaksanaan mobilisasi dini.

Hasil penelitian ini sesuai dengan Notoatmodjo, ${ }^{12}$ yang mengatakan bahwa pengetahuan dipengaruhi oleh pengalaman yang merupakan sumber pengetahuan atau pengalaman itu merupakan suatu cara untuk memperoleh kebenaran pengetahuan. Hal ini dilakukan dengan cara mengulang kembali pengalaman yang diperoleh dalam memecahkan permasalahan yang dihadapi pada masa yang lalu. Teori Hidayat $^{5}$ mengatakan bahwa pengetahuan seseorang berhubungan dengan pendidikan, semakin tinggi tingkat pendidikan seseorang semakin mudah menerima informasi sehingga semakin banyak pengetahuan yang dimiliki, sebaliknya pendidikan yang kurang akan menghambat perkembangan sikap seseorang terhadap nilai yang baru. Kurang pengetahuan akan pentingnya mobilisasi dini, menyebabkan banyak dari ibu post sectio caesarea tidak segera melakukan mobilisasi dini. 
Hasil penelitian ini diperkuat dengan hasil penelitian yang dilakukan oleh Ita Sasmita Buhari ${ }^{13}$ yang mengatakan bahwa menunjukkan adanya hubungan yang bermakna antara pengetahuan dengan mobilisasi dini pada ibu post SC dengan nilai $\mathrm{p}=0,00$. Dan diperkuat dengan hasil penelitian Remita Yuli Kusumaningrum, ${ }^{14}$ yang juga mengatakan adanya hubungan yang bermakna antara pengetahuan dengan mobilisasi dini pada ibu post SC dengan nilai $\mathrm{p}=0,05$

Menurut pendapat peneliti di RS Anna Medika Bekasi sebagian besar responden yang berpengetahuan baik dan melakukan mobilisasi dini, hal ini dikarenakan ibu dengan pengetahuan baik sudah pasti mendapatkan informasi tentang mobilisasi dini dengan baik sehingga mereka memiliki kemauan untuk segera bangun dari tempat tidurnya dan berkeinginan untuk cepat sembuh. Bagi responden yang berpengetahuan cukup dan melakukan mobilisasi dini, hal ini dikarenakan ibu dengan pengetahuan cukup sudah mendapatkan informasi tentang mobilisasi dini meskipun belum paham betul tentang mobilisasi dini tetapi mereka memiliki kemauan atau tidak untuk segera bangun dari tempat tidurnya dan berkeinginan untuk cepat sembuh. Dan bagi responden yang berpengetahuan kurang sebagian besar tidak melakukan mobilisasi dini, hal ini dikarenakan ibu dengan pengetahuan kurang belum mendapatkan informasi dan belum memiliki pengalaman untuk melakukan mobilisasi dini.

Hasil cross tabulasi antara variabel dukungan suami dengan mobilisasi dini menunjukan hasil uji statistik Chi-Square diperoleh nilai $p$ value 0,007 (p.value < 0,05) yang berarti Ho ditolak dan $\mathrm{Ha}$ diterima artinya ada hubungan yang bermakna antara dukungan suami dengan pelaksanaan mobilisasi dini.

Hasil penelitian ini sesuai dengan teori Friedman, ${ }^{15}$ yang mengatakan bahwa dukungan yang diberikan suami merupakan salah satu bentuk interaksi sosial yang didalamnya terdapat hubungan yang saling memberi dan menerima bantuan yang bersifat nyata, bantuan tersebut akan menempatkan individuindividu yang terlibat dalam sistem sosial yang pada akhirnya akan dapat memberikan cinta, perhatian maupun sense of attachment baik pada keluarga sosial maupun pasangan. Dukungan moral seorang suami pada istrinya hal yang memang dibutuhkan dan sangat dianjurkan suami memberikan dukungan atau motivasi yang lebih besar kepada istrinya.

Hasil penelitian ini sesuai dengan Nidya, ${ }^{10}$ yang mengatakan bahwa semakin tinggi dukungan suami akan semakin baik pula pelaksanaan mobilisasi dininya dan sebaliknya semakin rendah dukungan keluarga akan semakin kurang pula pelaksanaan mobilisasi dininya. dukungan suami mempunyai peranan penting terutama bagi ibu selama proses kehamilan sampai masa nifas sangat diperlukan karena dapat mengurangi rasa cemas, takut, serta dapat mendorong suasana tenang dan tentram bagi istri.

Berdasarkan hasil penelitian yang dilakukan oleh Rizky Arum Sari, ${ }^{11}$ di RSU Dr. Wahidin Sudiro Husodo Kabupaten Mojokerto mengatakan bahwa adanya hubungan yang bermakna antara dukungan suami dengan mobilisasi dini pada ibu post $\mathrm{SC}$ dengan nilai $\mathrm{p}=0,002$. Hasil penelitian Nidya, ${ }^{10}$ juga mengatakan adanya hubungan yang bermakna antara dukungan suami dengan mobilisasi dini pada ibu post $\mathrm{SC}$ dengan nilai $\mathrm{p}=0,000$.

Menurut pendapat peneliti di RS Anna Medika Bekasi sebagian besar responden mendapatkan dukungan dari suami dalam pelaksanaan mobilisasi dini, hal ini dikarenakan ibu yang mendapatkan dukungan dari suami memiliki kemauan yang lebih besar dalam melaksanakan mobilisasi dini dengan baik. Bagi responden yang tidak mendapatkan dukungan dari suami sebagian besar responden melaksanakan mobilisasi dini, hal ini dikarenakan biarpun responden tidak mendapatkan dukungan dari suami 
tetapi responden mendapatkan dukungan dari tenaga kesehatan yang menganjurkan dan mengajarkan kepada responden untuk melaksanakan mobilisasi dini supaya responden cepat bisa berdiri dan bangun dari tempat tidurnya. Bagi responden yang tidak melaksanakan mobilisasi dini mereka tidak memiliki kemauan dan merasa takut untuk melaksanakan mobilisasi dini sehingga mereka tidak berusaha untuk segera bangun dari tempat tidurnya.

\section{Kesimpulan}

Ada hubungan yang bermakna antara pengetahuan ibu post sectio caesarea dengan pelaksanaan mobilisasi dini dengan nilai $p$ value 0,001 . Ada hubungan yang bermakna antara dukungan suami dengan pelaksanaan mobilisasi dini dengan nilai $p$ value 0,007. Diharapkan kepada suami agar memberikan dukungan kepada pasien pasca operasi SC. Dukungan dapat diberikan dengan memberikan motivasi, semangat serta menemani pasien. Hal ini bertujuan agar pasien dapat sembuh dengan waktu yang retalive cepat. Pasien dapat menerapkan pengetahuan yang dimiliki tentang manfaat mobilisasi dini bagi ibu post SC sehingga proses penyembuhan dapat berjalan dengan cepat tanpa ada komplikasi.

\section{Daftar Pustaka}

1. Irawan.http://wartakesehatan.co.id/48612/angka -kematian-ibu-masih-tinggi-cita-cita-ra-kartinibelum-tercapai; 2015.

2. Kemenkes RI. Laporan Tahunan Direktorat Kesehatan Keluarga Tahun 2016. Jakarta. 2016

3. Julia.http://sinarharapan.co/news/read/15040725 0/papua-gencet-angka-kematian-anak; 2015.

4. Depkes RI. Profil Kesehatan Provinsi DKI Jakarta Tahun 2014. Jakarta; 2015.

5. Hidayat, A. \& Musrifatul, U. Buku Ajar Kebutuhan Dasar Manusia (KDM), Pendekatan Kurikulum Berbasis Kompetensi. Surabaya: Health Books Publishing; 2013.
6. Marmi. Asuhan Kebidanan pada Masa Nifas "Peurperium Care". Yogyakarta: Pustaka Pelajar; 2014.

7. Sulistiyawati, A. Buku Ajar Asuhan Kebidanan Pada Ibu Nifas. Yogyakarta: CV Andi Offset; 2013.

8. Fitriani, S.. Promosi kesehatan. Yogyakarta: Graha ilmu; 2013.

9. Setyowati. Karakteristik Yang Mempengaruhi Mobilisasi Dini Pada Ibu Nifas Post Sectio Caesarea, Embrio, Jurnal Kebidanan, gol. II; 2013.

10. Nindya A, Hubungan Dukungan Suami Dengan Pelaksanaan Mobilisasi Dini Pada Ibu Post Sectio Caesarea; 2017.

11. Rizky Arum Sari. Hubungan Dukungan Keluarga Dengan Mobilisasi Dini Ibu Nifas di RSU Dr.Wahidin Sudiro Husodo Kabupaten Mojokerto; 2015.

12. Notoatmodjo, S. Pendidikan dan Perilaku Kesehatan. Jakarta: Rineka Cipta; 2014.

13. Ita Sasmita Buhari. Hubungan Tingkat Pengetahuan Dengan Mobilisasi Dini Pada Ibu Nifas Di Puskesmas Likupang Timur Kecamatan Likupang Timur; 2014.

14. Remita Yuli Kusumaningrum. Hubungan Pengetahuan Ibu Post Partum Dengan Tindakan Mobilisasi Dini Pada Pasien Pasca Operasi Seksio Sesarea (Di Ruang Bersalin Rsud Kertosono); 2013.

15. Friedman, M. Buku Ajar Keperawatan keluarga: Riset, Teori, dan Praktek. Edisi ke-5. Jakarta: EGC; 2012. 